\title{
Het strafrecht en de overtuiging
}

\author{
B.F. Keulen*
}

\section{Inleiding}

Overtuiging betekent volgens de dikke Van Dale onder meer 'vaststaande mening omtrent iets'. 'Dit is mijn overtuiging' wordt uitgelegd als 'hiervan ben ik zeker, dit is mijn onwrikbaar gevoelen'. Daarmee is ook de overtuigingsdader gekarakteriseerd: een persoon die een strafbaar feit begaat als uitvloeisel van zijn vaststaande mening omtrent iets, zijn onwrikbaar gevoelen.

In het algemeen zijn wij geneigd het hebben van een overtuiging als iets positiefs te zien. Nog niet eens zo heel lang geleden sprak naar ik meen voetbaltrainer Van Gaal over de 'patatgeneratie'. Dat begrip stond voor een generatie verwende jongere voetballers, zonder veel wilskracht en overtuiging. De kritiek van Van Gaal kon bij velen op instemming rekenen. Mensen met sterke overtuigingen, die daar veel voor over hebben, roepen bij velen juist positieve gevoelens op. Krijgen die positieve gevoelens in het strafrecht een vertaling?

\section{Overtuiging en strafbaarheid}

Kan de omstandigheid dat een daad is begaan uit overtuiging strafuitsluitend werken, bijvoorbeeld? De Hoge Raad heeft in het verleden aangegeven dat een beroep op gewetensbezwaren een verweer is in de zin van artikel 358, derde lid, Sv. In 1951 werd in die zin beslist in het arrest dat wel wordt aangeduid als Alphense boer. ${ }^{1}$ Deze boer was veroordeeld op grond van het Besluit bestrijding tuberculose. Hij had runderen onder zijn beheer en toe-

* Berend Keulen is hoogleraar straf- en strafprocesrecht aan de Rijksuniversiteit Groningen.

1 HR 20 juni 1950, NJ 1951/348. 
zicht gehad zonder dat hij aangesloten was bij een erkende provinciale gezondheidsdienst. Hij had zich niet aangesloten vanwege gewetensbezwaren. Op zijn beroep op gewetensbezwaren moest uit hoofde van artikel 358, derde lid, Sv in het vonnis ingegaan worden. ${ }^{2}$

In de Alphense boer werd niet duidelijk van welke soort strafuitsluitingsgrond sprake zou kunnen zijn. Later is een dergelijk beroep dikwijls opgevat als een beroep op overmacht. Illustratief is een arrest uit $1968 .{ }^{3}$ De verdachte, een Quaker, stond in deze zaak terecht wegens het op de openbare weg een optocht houden. Hij stelde ter terechtzitting: 'Wij, Quakers, willen hier op deze wereld opkomen voor de lijdende mensheid, en ikzelf kan niet anders. Voor mij betreft het hier een soort processie of begrafenisstoet. Ik beroep mij ten deze op persoonlijke godsdienstige gedrevenheid waaraan ik geen weerstand vermag te bieden.' De rechtbank vatte dit op als een beroep op overmacht. De Hoge Raad meende dat de rechtbank dit verweer inderdaad zo had kunnen opvatten.

Op verweren die betogen dat strafbare feiten uit overtuiging begaan zijn en dat die overtuiging tot strafuitsluiting leidt, moet dus in het vonnis ingegaan worden. Maar tot strafuitsluiting hebben dergelijke verweren, los van situaties waarin de wetgever voorzieningen voor gewetensbezwaren heeft getroffen, bij mijn weten nooit geleid. ${ }^{4}$

Iets anders is, dat mensen in sommige gevallen handelen vanuit een juiste overtuiging. Ik noem de Huizer veearts, een arrest uit $1933 .{ }^{5}$ In dat arrest, de juristen onder $U$ bekend, was een veearts tot een boete van vijftig cent veroordeeld wegens overtreding van de Veewet. Hij had zeven gezonde koeien in verdachte toestand gebracht door ze in de buurt te brengen van koeien die aan mond- en klauwzeer leden. Hij beriep zich er op dat hij in de omstandigheden van het geval als veearts goed en verantwoord had gehandeld. De Hoge Raad meende dat volgens artikel 82 Veewet niet kon worden gestraft de veearts die 'handelt niet slechts volgens hetgeen naar eigen inzicht geoorloofd en wetenschappelijk aangewezen is, doch ook volgens in zijn wetenschap algemeen als juist erkende richtsnoeren', en vernietigde de veroordeling. Ging deze veearts vrijuit vanwege zijn overtuiging? Mijns inziens niet. Het was niet de overtuiging van de veearts die tot straffeloosheid aanleiding

2 Zie over dit arrest en over gewetensbezwaren in het strafrecht uitgebreider J. Remmelink, Handelingen NJV 1960, p. 20 e.v.

HR 16 januari 1968, NJ 1969/2.

Vgl. ook J. de Hullu, Materieel strafrecht, Kluwer, Deventer 2003, p. 300.

HR 29 februari 1933, NJ 1933, p. 918 e.v. m.nt. T. 
kon geven, maar zijn juiste belangenafweging. Het ging uiteindelijk om het handelen volgens in zijn wetenschap als juist erkende richtsnoeren.

\section{Overtuiging en strafmaat}

Het ligt ook niet in de rede dat mensen die strafbare feiten uit overtuiging begaan er beter van af komen dan mensen die dezelfde feiten zonder overtuiging begaan. Anders wordt het hebben van een overtuiging al gauw erg aantrekkelijk. Hoe onderkent men echte gewetensbezwaren? Remmelink, die de dader handelend uit gewetensbezwaren in 1960 typeert als een bepaald type overtuigingsdader, noemt dit één van de twee grote moeilijkheden op dit gebied. ${ }^{6}$

Ter illustratie wil ik wijzen op de strenge straffen die in het verleden aan totaalweigeraars werden opgelegd. De 18-jarige die niet in militaire dienst wilde vanwege pacifistische idealen, mocht er niet beter vanaf komen dan zijn leeftijdgenoot die liever een goed salaris ging verdienen. Anders zou de laatste ook heel snel pacifist kunnen worden. Daar kwam bij dat met de overtuiging van dienstweigeraars in zoverre rekening werd gehouden dat zij vervangende dienst konden doen. Vanwege die bijzondere regeling stond aan de dienstplichtige geen beroep op strafuitsluiting wegens gewetensbezwaren open. ${ }^{7}$

Er kan zelfs reden zijn om daders die hun daad begaan hebben als uitvloeisel van hun overtuiging, binnen de bandbreedte die spoort met de ernst van het feit harder te straffen. Bij wijze van voorbeeld noem ik het vonnis van de rechtbank in de zaak tegen Mohammed B. Mohammed B. werd door de rechtbank gekenschetst als 'een overtuigingsdader, die een radicale interpretatie van de islam aanhangt'. ${ }^{8}$ Mede omdat Mohammed B., zo meende de rechtbank, niet van plan was zijn manier van denken in heroverweging te nemen, kwam zij tot het 'oordeel dat vanuit oogpunt van speciale preventie

6 Remmelink, a.w., p. 10, 47. Remmelink verwerpt in zijn conclusie, p. 75, het gewetensbezwaar als criterium voor het oordeel over de schuld omdat de overheid 'zich van een beoordeling van godsdienstige en daarmee in een gemengde staat (...) gelijk te stellen andere heilige gevoelens heeft te onthouden, in elk geval, wanneer kennisneming onvermijdelijk is zoveel mogelijk de schijn moet vermijden over het geweten in absolute zin te oordelen - daargelaten nog alle practische bezwaren.'

7 Vgl. HR 17 mei 1988, NJ 1989/230. Vgl. ook HR 19 maart 1996, NJ 1996, NJ 1996/480, volgens de conclusie van AG Fokkens de eerste van enkele honderden zaken tegen zogenaamde ‘weigeryuppen' die zowel militaire als vervangende dienst wilden ontlopen.

8 Rechtbank Amsterdam 26 juli 2005, LJN AU 0025. 
geen reëel uitzicht bestaat op resocialisatie van verdachte en terugkeer in de samenleving zonder dat dit een onaanvaardbaar gevaar met zich meebrengt.' De samenleving moest, zo besliste de rechtbank, maximaal worden beschermd. Zij legde als bekend levenslange gevangenisstraf op.

\section{Strafdoelen}

De rechtbank kwam hier dus tot levenslange gevangenisstraf met een motivering die op speciale preventie is toegesneden. Ik heb me afgevraagd of dat bij overtuigingsdaders inderdaad het centrale strafdoel vormt. Daar heb ik toch enige twijfels bij. Voor mijn gevoel gaat het bij overtuigingsdaders net zozeer om een ander aspect. De overtuigingsdader stelt zijn overtuiging boven de wet. Hij stelt de gelding van die wet daarmee ter discussie. De straf moet dan duidelijk maken dat de geldigheid van de norm boven elke discussie verheven is. Men kan dit in verband brengen met generale preventie, normbevestiging en afschrikking. ${ }^{9}$

Het gaat daarbij niet alleen om het directe preventieve effect op derden. Want het staat voor mij niet vast dat volgers van Mohammed B. zich aan een langere vrijheidsstraf iets gelegen laten liggen. Het effect is, verwacht ik, meer indirect. Een snelle en rechtvaardige strafrechtspleging, die dergelijke misdrijven hard bestraft, dwingt respect af. Dat heeft voor de hele samenleving een positief effect.

Dit strafdoel van generale preventie en normbevestiging speelt ook bij misdrijven die uit eerwraak worden gepleegd. Ook deze daders kan men overtuigingsdaders noemen: personen die een strafbaar feit begaan als uitvloeisel van hun vaststaande mening omtrent wat zedelijk ongeoorloofd is. Knoops heeft in zijn dissertatie besproken of bij eerwraak sprake kan zijn van overmacht. Hij heeft die gedachte niet verworpen. ${ }^{10}$ Ik zie voor het aanvaarden van overmacht bij eerwraak geen ruimte. De drang om vanuit de eigen overtuiging eerwraak te plegen is een drang waaraan weerstand gebo-

9 J. de Hullu, Materieel strafrecht, Kluwer, Deventer 2003, p. 5. Specifiek bij terrorisme kan de overtuiging in verband staan met het terroristisch oogmerk, waaronder valt: het oogmerk om `een overheid (...) wederrechtelijk te dwingen iets te doen, niet te doen of te dulden'. Dat oogmerk brengt bij terroristische misdrijven een verhoging van het wettelijke strafmaximum mee.

10 G.G.J. Knoops, Psychische overmacht en rechtsvinding, Deventer 1998, p. 253 e.v., vooral p. 262. 
den moet worden. ${ }^{11}$ Strenge straffen voor daders van eerwrak kunnen er bij helpen, dat besef te laten doordringen. De zwaarte van de straf moet duidelijk maken dat de norm niet ter discussie staat.

\section{Detentieperikelen}

\section{Inrichting en regiem}

De bijzondere positie van de overtuigingsdader houdt niet op nadat het vonnis gewezen is. Enkele decennia geleden is een groep Molukkers die men ook overtuigingsdaders kan noemen, gedetineerd geweest na de treinkapingen. Ik heb Klaas van Tuinen daar eens kort een vraag over gesteld, bij het voorbereiden van deze lezing. Uit wat hij zei begreep ik dat de situatie toen eigenlijk zo was dat voorkomen moest worden dat de Molukse daders negatief werden beïnvloed door de andere gedetineerden.

Op dit moment speelt vooral het omgekeerde probleem, en daar wil ik me dan ook op richten. De islamistische overtuigingsdader is niet alleen overtuigd van het eigen gelijk, hij wil ook anderen daar dikwijls van overtuigen. Justitie staat voor de vraag, in hoeverre daar bij de tenuitvoerlegging van de vrijheidsstraf rekening mee dient te worden gehouden, bijvoorbeeld door de contacten tussen gedetineerden te beperken. Dat speelt ook bij Mohammed B.

De regelgeving is thans slechts in beperkte mate op dit probleem toegesneden. Plaatsing in een extra beveiligde inrichting (ebi) en het daaraan gekoppelde regime is mogelijk bij gedetineerden die een extreem vluchtrisico vormen of bij ontvluchting een onaanvaardbaar maatschappelijk risico vormen. Van een extreem vluchtrisico behoeft bij overtuigingsdaders geen sprake te zijn. Ontvluchting kan onder omstandigheden wel een onaanvaardbaar maatschappelijk risico zijn. Maar plaatsing in een ebi enkel op deze tweede grond kan op de langere termijn, ook gelet op het EVRM, niet de oplossing zijn. ${ }^{12}$ En in ieder geval kan de wens de contacten van de overtuigingsdader met andere gedetineerden te beperken geen grond vormen voor plaatsing in een ebi.

11 Vgl. HR 30 november 2004, NJ 2005/94, m.nt. PMe, waarin de Hoge Raad aangeeft dat de voorwaarden voor psychische overmacht inhouden 'dat sprake moet zijn van een van buiten komende drang waaraan de verdachte redelijkerwijze geen werstand kon en ook niet behoefde te bieden.'

12 Vgl. ook de toelichting op artikel 6 Regeling selectie, plaatsing en overplaatsing van gedetineerden, Stcrt. 12 september 2000, die de nadruk legt op extreem vluchtgevaar. 
Gedetineerden kunnen voorts in een individueel regime worden geplaatst indien zij op grond van hun persoonlijkheid, gedrag of andere persoonlijke omstandigheden een ernstig beheersrisico vormen voor zichzelf of voor anderen en ten gevolge daarvan niet in staat zijn in een regime van algehele of beperkte gemeenschap te functioneren of te verblijven. ${ }^{13}$ Kern is dus het beheersrisico. Is dat bij overtuigingsdaders in het geding? Denkbaar is dat de overtuigingsdader de gedetineerden die hij probeert te overtuigen op het hart bindt zich in de inrichting vooral gedeisd te houden. Verder moet de gedetineerde als een gevolg van het beheersrisico niet in staat zijn in een regime van gemeenschap te verblijven. Is daar bij de overtuigingsdader aan voldaan? Zou hij zich, juist als hij succes heeft met het winnen van anderen voor zijn denkbeelden, niet betrekkelijk goed in de groep gedetineerden thuis kunnen voelen?

Verder kan een ordemaatregel of een disciplinaire straf worden opgelegd indien de gedetineerde activiteiten ontplooit die onverenigbaar zijn met de orde en veiligheid in de inrichting dan wel met de ongestoorde tenuitvoerlegging van de vrijheidsbeneming. ${ }^{14}$ De ordemaatregel of disciplinaire straf kan bestaan uit uitsluiting van deelname aan activiteiten of uit plaatsing in een afzonderingscel. Maar een ordemaatregel kan, als er al voldoende aanleiding is haar op te leggen, slechts voor beperkte tijd worden toegepast.

\section{Bejegening}

De vraag rijst vervolgens of het wenselijk is meer expliciet rekening te houden met de overtuigingsdader die anderen wil overtuigen of, zo u wilt, rekruteren voor de jihad. De Minister van Justitie onderzoekt volgens een antwoord op kamervragen de wenselijkheid van een speciaal detentieregime. ${ }^{15}$ Hij noemt daarbij zijn 'bevoegdheid om inrichtingen of afdelingen daarvan te bestemmen voor de onderbrenging van gedetineerden die een bijzondere opvang behoeven.' Die bijzondere opvang kan, gelet op artikel 14 Penitentiaire beginselenwet, verband houden met de leeftijd, de persoonlijkheid, de lichamelijke of geestelijke gezondheidstoestand van de gedetineerden, alsmede het delict waarvoor zij zijn gedetineerd.

Een bijzondere opvang van islamistische overtuigingsdaders lijkt mij in beginsel niet onaanvaardbaar. De tenuitvoerlegging van de gevangenisstraf

13 Artikel 11 Regeling selectie, plaatsing en overplaatsing van gedetineerden, Stcrt. 12 september 2000. Vgl. voor het individueel regime ook artikel 22 Penitentiaire beginselenwet.

14 Artikelen 23, 50 Penitentiaire beginselenwet.

15 Kamervragen II 2004/05, 1839. 
moet dienstbaar zijn aan de doelen die met de oplegging nagestreefd worden. Generale preventie behoort tot deze doelen. Daarbij past op zichzelf dat veroordeelden die anderen tot gevaarlijke overtuigingen willen brengen beperkt kunnen worden in hun contacten.

Een argument voor een speciale opvang kan ook gelegen zijn in het versterken van het vertrouwen bij het publiek in de tenuitvoerlegging van de gevangenisstraf. Zelfs als ook zonder een speciale opvang een concentratie van overtuigingsdaders bereikt zou kunnen worden, kan creatie van een bijzondere opvang uit dat oogpunt een meerwaarde hebben.

Ik durf niet onmiddellijk te beoordelen of het gezamenlijk vastzetten van gelijkgezinde overtuigingsdaders uit oogpunt van speciale preventie de meest effectieve vorm van tenuitvoerlegging is. Het vastzetten van mensen met dezelfde overtuiging in één afdeling zou ook tot gevolg kunnen hebben dat de overtuiging zich meer vastzet. Misschien mag ik een korte anekdote vertellen. Een voormalig collega van mij op het departement, Hans Bevers, is op bezoek geweest bij het Rwanda-tribunaal, en ontdekte ergens dat in één gevangenis alle leden van een kabinet dat in functie was ten tijde van de genocide waren gedetineerd. En het aparte was, vertelde hij, dat ze zich gedroegen alsof ze nog steeds in functie waren. Ze hielden kabinetsvergaderingen en namen beslissingen. Die werden alleen niet meer onmiddellijk uitgevoerd. Zo kan, stel ik me voor, ook een groep verwante overtuigingsdaders die samen worden gedetineerd, vastroesten in bepaalde patronen. Anderzijds: als er een of een paar afvalligen komen, kan dat anderen wellicht ook aan het twijfelen brengen.

Een vraag is nog of het huidige artikel 14 Penitentiaire beginselenwet een voldoende precieze basis biedt voor een bijzondere opvang van islamistische overtuigingsdaders. Het meest in aanmerking komende criterium van dat artikel is - denk ik - het gepleegde delict. Gedacht zou kunnen worden aan terroristische misdrijven als selectiecriterium. Maar wat dan als iemand die wegens een ander delict is veroordeeld, zeer effectief in het rekruteren blijkt te zijn? Zou het niet beter zijn om, als toch een bijzondere opvang gecreëerd wordt, een beter passend wettelijk criterium te introduceren, bijvoorbeeld het gevaar voor rekrutering?

\section{Gedragsbeïnvloeding}

$\mathrm{U}$ zal duidelijk zijn geworden dat ik het als een wenselijk effect van de tenuitvoerlegging zie dat overtuigingsdaders afstand nemen van overtuigingen die hen tot ernstige delicten hebben gebracht. Daarvoor pleit een argument van speciale preventie, maar ook van generale preventie. De aantrek- 
kingskracht van overtuigingsdaders voor navolgers kan gaan eroderen als zou blijken dat er ook een weg terug is. En dat sommigen die weg ook volgen.

Wij moeten er naar mijn mening evenwel terughoudend mee zijn de tenuitvoerlegging aan het bereiken van dat effect dienstbaar te maken. Geen structurele gespreksvoering die beïnvloeding tot doel heeft. Dat past niet bij een behoorlijke tenuitvoerlegging. ${ }^{16}$ Even belangrijk is misschien wel dat ik ook twijfel aan de effectiviteit van pogingen tot gedragsbeïnvloeding. Zou twijfel niet een betere kans hebben om wortel te schieten als de betrokkene meer met rust wordt gelaten? Maar dit is psychologie van de koude grond, om in aardse sferen te blijven.

$\mathrm{U}$ moet bij mijn opmerkingen wellicht denken aan gedachten die vroeger leefden ten aanzien van eenzame opsluiting. Die eenzame opsluiting zou een heilzaam effect hebben op de veroordeelde. Daarom voor alle duidelijkheid: mijn ideaal is niet een individueel regime voor overtuigingsdaders. Al vind ik het niet onaanvaardbaar om veroordeelden die anderen tot gevaarlijke overtuigingen willen brengen in ieder geval tijdelijk in een individueel regime te plaatsen.

Van groot belang lijkt mij vooral dat voldoende zorg wordt besteed aan de begeleiding van overtuigingsdaders. Daarbij past speciale aandacht voor de geestelijke weerbaarheid van PIW'ers die met overtuigingsdaders werken. Zij zouden in staat moeten zijn hun gereformeerde, katholieke, atheïstische of misschien juist ook wel islamitische levensovertuiging tegenover de overtuigingsdader staande te houden. Zou het niet de moeite waard zijn te zoeken naar stevige persoonlijkheden, rolmodellen die gedurende een jarenlange detentie hun uitwerking op de overtuigingsdader kunnen hebben?

Aan specifieke voorzieningen voor detentie van overtuigingsdaders hangt vanzelfsprekend een prijskaartje. Maar als die prijs gerechtvaardigd wordt door een vermindering van het risico van ernstige misdrijven kan daar plaats voor zijn.

16 Vgl. ook artikel 2, vierde lid, van de Penitentiaire beginselenwet: personen ten aanzien van wie de tenuitvoerlegging plaatsvindt van een vrijheidsstraf of vrijheidsbenemende maatregel worden aan geen andere beperkingen onderworpen dan die welke voor het doel van de vrijheidsbeneming of in het belang van de handhaving van de orde of de veiligheid in de inrichting noodzakelijk zijn. 


\section{Strafrecht als instrument}

Met deze bespreking van het detentieregime gaan we al meer van de daad naar de overtuiging. In hoeverre kan binnen het strafrecht worden opgetreden tegen die achterliggende overtuiging? Daar wil ik nog een paar dingen over zeggen.

Van een door velen gedeelde overtuiging die tot strafbare feiten leidt, kan een grote dreiging uitgaan. Dhr. Andries Knevel had een tijdje geleden een interview met dhr. Abdul-Jabbar van de Ven. Daarin gaf de laatste aan dat hij er niet rouwig om zou zijn als het kamerlid Wilders aan een ernstige ziekte zou komen te overlijden. ${ }^{17}$ Dat leidde tot grote commotie. Strafbaar waren deze uitlatingen niet. Want de mogelijkheden om met het strafrecht iets te doen tegen meningsuitingen zijn beperkt. Het hebben van overtuigingen is niet strafbaar. En ook aan strafbaarstelling van het uiten van overtuigingen zijn in een samenleving die de vrijheid van meningsuiting respecteert nauwe grenzen gesteld. De mogelijkheden van het strafrecht worden pas groter als een begin wordt gemakt met het omzetten van een overtuiging in daden.

De afgelopen jaren zijn de grenzen van strafbaarheid in verband met de dreiging van terrorisme op een aantal punten verruimd. Zo is de strafbare voorbereiding uitgebreid. En samenspanning tot de ernstigste terroristische misdrijven is strafbaar gesteld. ${ }^{18}$ Daartegen is in de strafrechtelijke literatuur verzet geweest, maar minder dan misschien had kunnen worden verwacht. Zou dit komen omdat de verruimde grenzen van de strafbaarheid vooral voor overtuigingsdaders van belang zijn? Een argument tegen strafbaarheid van voorbereiding en samenspanning kan zijn dat er nog zoveel gelegenheden zijn om van uitvoering af te zien. Maar dat argument maakt minder indruk als toch niet verwacht wordt dat de betrokkenen halverwege tot inkeer zullen komen.

Ik wil nog een observatie met $\mathrm{u}$ delen. Te oordelen naar de reacties vonden velen het onbegrijpelijk dat Samir A. werd vrijgesproken van voorbereiding van terroristische aanslagen. ${ }^{19}$ Zijn overtuiging om tot dergelijke aanslagen

17 Vgl. bijvoorbeeld www.planet.nl.

18 Wet van 20 december 2001 tot uitvoering van het op 9 december 1999 te New York totstandgekomen Internationaal Verdrag ter bestrijding van de financiering van terrorisme (Trb. 2000, 12), Stb. 675, in werking getreden 1 januari 2002 (besluit van 20 december 2001, Stb. 703); Wet terroristische misdrijven, Stb. 2004, 290, in werking getreden 10 augustus 2004 (besluit van 21 juli 2004, Stb. 373).

19 Rechtbank Rotterdam 6 april 2005, LJN AT 3315. 
te komen was hen duidelijk gebleken. Dat deze zich niet in strafbare voorbereiding geconcretiseerd had, was geen geruststelling maar een teleurstelling. Wat zegt dat over de grenzen van de strafbaar te oordelen voorbereiding bij terroristische aanslagen? Zou het zo zijn dat voor velen toereikend is dat uit feiten en omstandigheden voldoende bewijs volgt van gedragingen waaruit de overtuiging blijkt die voor het plegen van dergelijke aanslagen nodig is? Ik wil ook attenderen op een motie van D66 en GroenLinks. Daarin wordt de regering gevraagd om 'te voorzien in een strafbaarstelling van het volgen van buitenlandse scholing in het aanwenden van terroristisch geweld. ${ }^{20}$ Concrete voorbereiding van een concrete aanslag hoeft dan nog niet in beeld te zijn. Wel kan uit het volgen van buitenlandse scholing in het aanwenden van terroristisch geweld worden afgeleid dat betrokkene de overtuiging heeft om een aanslag te plegen.

Tenslotte wil ik het concept-wetsvoorstel inzake de bestuurlijke maatregelen op het terrein van terrorismebestrijding noemen. ${ }^{21}$ Dat wil het volgens de aankondiging mogelijk maken dat aan mensen die zich niet schuldig hebben gemaakt aan een strafbaar feit, maar van wie wel gedragingen bekend zijn die wijzen op mogelijke bereidheid tot het plegen van terroristische aanslagen, zoals het volgen van scholing in het aanwenden van terroristisch geweld, beperkingen worden opgelegd. Gedacht wordt aan gebiedsverboden en aan verboden om in de nabijheid van nader aangeduide personen te zijn. Gaat het er hier in feite ook niet om dat gedragingen waaruit een gevaarlijke overtuiging blijkt, de bestuurlijke sancties dragen?

Of dit wenselijke ontwikkelingen zijn, daarover verschillen wellicht de meningen. Ik wijs er nog op, dat het Wetboek van Strafrecht een aanknopingspunt biedt om strafbare voorbereiding van terrorisme anders te benaderen dan strafbare voorbereiding van 'gewone' ernstige criminaliteit. In artikel 96, tweede lid, Sr, is een specifieke selectie strafbare voorbereidingshandelingen opgenomen voor de ernstigste misdrijven die ons recht kent.

Een volgende verruiming van de strafbaarheid betreft de voorgenomen strafbaarstelling van apologie. Daar gaat het om het verheerlijken, vergoelijken, bagatelliseren of ontkennen van sommige ernstige misdrijven, waaronder terroristische. ${ }^{22}$ Dit voorstel kan worden geplaatst als een verruiming ten opzichte van de strafbaarstelling van opruiing tot strafbare feiten.

20 Handelingen II 2004/05, 29 754, nr. 15.

21 Aangekondigd in Kamerstukken II 2004/05, 29 754, nr. 5.

22 Eveneens aangekondigd in Kamerstukken II 2004/05, 29 754, nr. 5. Vgl. voor het concept-wetsvoorstel www.justitie.nl. 
De rechtspraak over opruiing is hoofdzakelijk van oudere datum. Een belangrijk arrest uit 1916 heeft betrekking op iemand die we nu ook een overtuigingsdader zouden noemen. ${ }^{23}$ De verdachte, een predikant, had gepoogd anderen door het verspreiden van een manifest over te halen dienst te weigeren. Dat werd in verband met de Eerste Wereldoorlog hoog opgenomen. Het opruiende karakter van het geschrift lag in dit geval in het uiting geven aan hoge morele waardering voor een strafbare handeling, het dienstweigeren.

Het rechtskarakter van opruiing brengt met zich mee dat het moet gaan om het uiting geven aan hoge morele waardering voor een nog te begaan strafbaar feit. Opruien in deze vorm kan soms wellicht worden afgeleid uit het aanprijzen van reeds gepleegde delicten. Maar niet elk verheerlijken van een gepleegd delict levert het opruien tot een nog te plegen vergelijkbaar delict op. Het verheerlijken van dienstweigeren voor dienstplichtige jonge mannen is nog iets anders dan het verheerlijken van een terroristische aanslag binnen een groep gelijkgestemden. De vreugde die sommigen toonden na 11 september was, hoe abject ook, nog geen aansporing tot navolging.

De voorgestelde strafbaarstelling van apologie brengt het verheerlijken van terroristische aanslagen binnen de grenzen van de strafwet. Vereist is dan overigens nog wel dat de dader weet of ernstige reden heeft om te vermoeden dat de openbare orde daardoor ernstig wordt of kan worden verstoord. ${ }^{24}$ Deze strafbaarstelling perkt de vrijheid van meningsuiting in, al brengt het EVRM mee dat deze inperking geringer is dan op het eerste gezicht wellicht lijkt. Of deze uitlatingen zo schadelijk zijn dat strafbaarstelling aangewezen is, laat ik aan de discussie over. Ik wijs er wel op dat Frankrijk een vergelijkbare strafbaarstelling heeft. ${ }^{25}$ De rechtsgrond behoeft niet alleen in de openbare orde te worden gezocht. Zij kan bijvoorbeeld ook liggen in het

23 HR 26 juni 1916, NJ 1916, 703. Vgl. over dit arrest ook Remmelink, a.w., p. 19.

24 Vgl. het concept-wetsvoorstel, gepubliceerd op www.justitie.nl.

25 Vgl. artikel 24 van de Franse Mediawet, met een maximale gevangenisstraf van 5 jaar. De bepaling luidt: "Seront punis des peines prévues par l'alinéa 1er ceux qui, par les mêmes moyens, auront provoqué directement aux actes de terrorisme prévus par le titre II du livre IV du code pénal, ou qui en auront fait l'apologie." De "moyen" zijn: "soit par des discours, cris ou menaces proférés dans des lieux ou réunions publics, soit par des écrits, imprimés, dessins, gravures, peintures, emblèmes, images ou tout autre support de l'écrit, de la parole ou de l'image vendus ou distribués, mis en vente ou exposés dans des lieux ou réunions publics, soit par des placards ou des affiches exposés au regard du public, soit par tout moyen de communication audiovisuelle". Duitsland kent een beperktere- strafbaarstelling van, kort gezegd, het in het openbaar of in een bijeenkomst billijken, ontkennen of bagatelliseren van bepaalde ernstige handelingen die zijn begaan onder de heerschappij van het nationaal-socialisme, voorzover daardoor de openbare rust kan worden verstoord (par. 130 lid 3 StGB). 
voorkomen van additioneel leed voor de nabestaanden van personen die bij aanslagen zijn omgekomen.

\section{Slot}

De wetgever zit dus niet stil. Maar duidelijk is dat de mogelijkheden van het strafrecht bij het bestrijden van gevaarlijke overtuigingen uiteindelijk toch vrij beperkt zijn. Bij radicalisering kunnen gefrustreerde ambities en ondergane vernederingen een belangrijke rol spelen. Voor het tegengaan van radicalisering is een antidiscriminatiebeleid, ook op de arbeidsmarkt, daarom misschien wel het allerbelangrijkst. Maar dat gaat de perken van mijn lezing te buiten. 